\title{
Sharing knowledge with Google Earth
}

\author{
Marine biologist Laura Stocker led experts in economics, policy and urban and regional planning to \\ develop a participatory approach to climate adaptation and sustainability at Rottnest Island, Australia.
}

\begin{abstract}
What was the main objective of the work at the beginning of the project?

This project is part of the ongoing Coastal Collaboration Cluster programme looking at the uptake of climate science into decision making for coastal adaptation, an area still lacking adequate policy commitment in Australia. We held a workshop in May 2010, commissioned by the Rottnest Island Authority - a statutory body controlling and managing the Island. We used the workshop to develop and test a participatory methodology, across a range of stakeholders, to identify areas of special management importance ('hotspots') from a sustainability and climate change perspective. Rottnest Island, located $20 \mathrm{~km}$ off the coast of Perth, Western Australia, is an icon due to its unique marine ecosystem, its cultural heritage, and its popularity as a national tourist destination. The Island is threatened by increasing tourism pressure and climate change. We used Google Earth - a freely available geographic information system that works as a multilayered web map service - to enable workshop participants to identify hotspots in terms of the social, economic, cultural and ecological features of the island. The idea was to create a digital mapping methodology readily accessible to the community and useful to explore possible pathways for adaptation.
\end{abstract}

\section{How did you go about finding suitable collaborators?}

There were different levels of collaboration. The core team of researchers who developed the transdisciplinary mapping exercise and workshop process are all known to each other and based at Curtin University. In addition I went to several other universities, local consultants and government agencies to build up the multidisciplinary group of expert speakers who provided the workshop participants with the relevant scientific information.

Did you encounter any difficulties in working with a team of experts with different research backgrounds?

I didn't find particular difficulties as most people I chose to work with are experts who fully understand the value of interdisciplinary research. Also, we had quite a number of workshop facilitators who were chosen on the basis of their understanding of the social, economic, cultural and ecological aspects of the issues under discussion. They had an incredibly challenging and critical role to play for the success of the workshop.

What was the highlight of working on this interdisciplinary project?

Google Earth enabled cognitive shifts in the workshop participants by identifying synergies among the different sustainability dimensions before going on to map the concerns and adaptive strategies, and this was really the highlight for me.

\section{Any surprises?}

It was a nice surprise finding out that the stakeholders involved in the project recognized how climate change affects everybody and is not just an environmental problem. Also, it was interesting that combining the use of a visual interface to create maps, with scientific information and the role of facilitators during the workshop, allowed us to manage potential conflicting

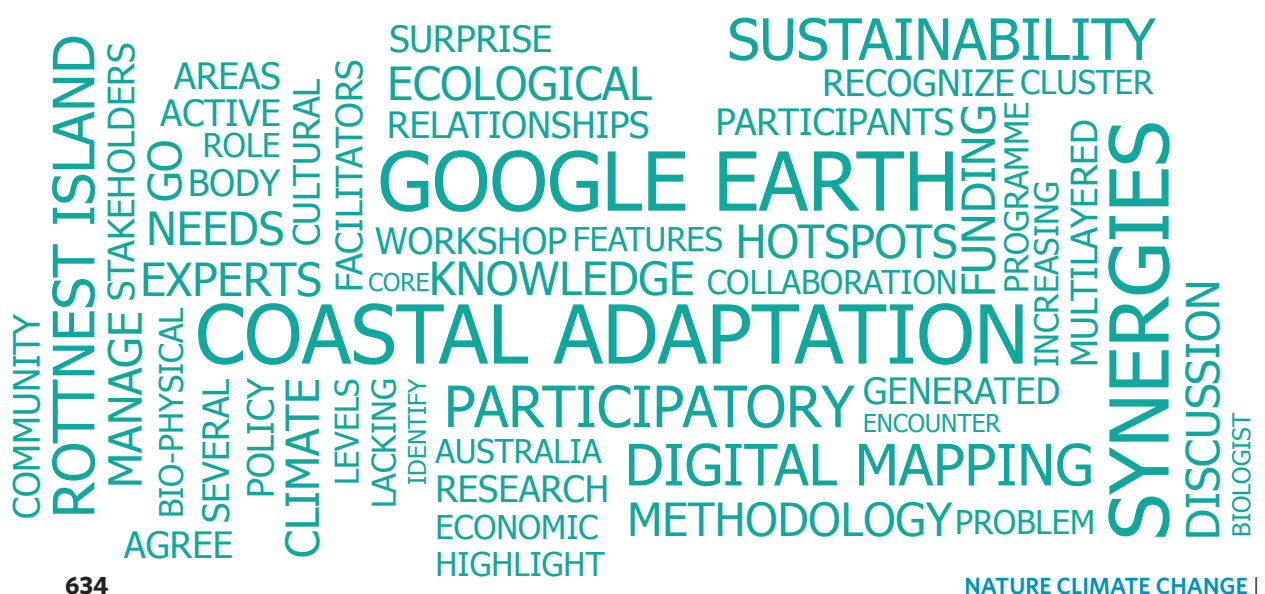

views during the project. Finally, it was good to see how the learning needs of the participants were met by the different learning opportunities the process generated.

\section{Did you learn any lessons about interdisciplinary collaboration from this project that would benefit others trying to do similar work?}

It is important to make sure the members of the core team all understand what the goals are and they agree on whether the work is going to be interdisciplinary, multidisciplinary or transdisciplinary (ours was all three). It is also important to have a clear shared framework that enables active mutual learning. Finally, you need to set extra time to talk as this is critical to understand each other's languages.

\section{Was it difficult to get the financial support for the study?}

A lot of the funding came through the Coastal Collaboration Cluster supported by the Commonwealth Scientific and Industrial Research Organisation (CSIRO) in Australia, which originally had a strong emphasis on bio-physical research but more recently has started to recognize the need for social science research in coastal adaptation to climate change. We were also lucky to receive funding from the Rottnest Island Authority. They had a real-world problem to address and were looking for a solution. Any time you have to address a real problem you need to pull in multiple disciplines and the Authority was quite comfortable with that approach.

\section{Any final thoughts?}

Climate change will not be solved with facts and figures alone: the hard science is necessary but not sufficient. The complexity and uncertainty are a challenge not only to conventional reductionist science, but to conventional decision making. Meaningful solutions will come through deliberations among the broader community, decisionmakers and knowledge holders.

\section{INTERVIEW BY MONICA CONTESTABILE}

This Beyond Boundaries article is linked to a research paper by Laura Stocker and colleagues, published in Ecol. Econ.

http://dx.doi.org/10.1016/j.

ecolecon.2012.04.024 (2012) 